\title{
Penentuan Lokasi dan Kapasitas Optimal SVC (Static VAR Compensator) untuk Meningkatkan Keamanan Tegangan
}

\author{
Habibur Rohman, Adi Soeprijanto, Rony Seto Wibowo \\ Departemen Teknik Elektro, Fakultas Teknologi Elektro, Institut Teknologi Sepuluh Nopember \\ Email: adisup@ee.its.ac.id
}

\begin{abstract}
Abstrak-Tujuan dari sistem transmisi adalah menyalurkan daya listrik dari pusat pembangkit ke pusat beban secara aman, efisien, handal dan ekonomis. Agar Penyediaan tenaga listrik dapat dilakukan dengan baik sistem tenaga listrik perlu memenuhi beberapa persyaratan diantaranya tegangan dan frekuensi yang stabil. Gangguan pada saluran transmisi dapat menyebabkan overload pada saluran, overvoltage dan undervoltage pada bus yang dapat mengancam keamanan dari sistem tenaga listrik. Dampak dari kontingensi pada tiap elemen sistem bermacammacam. Voltage performance index adalah salah satu index yang dapat digunakan untuk menentukan tingkat kontingensi pada tiap saluran transmisi. Pada studi ini analisis kontingensi diterapkan pada saluran $500 \mathrm{KV}$ Jawa-Bali untuk menentukan tingkat keparahan kontingensi dan untuk mengevaluasi dampak dari kontingensi terhadap sistem. Static VAR Compensator (SVC) merupakan FACTS device yang dipasang secara shunt pada bus untuk memperbaiki profil tegangan pada kasus kontingensi terburuk. Penempatan FACTS device yang kurang optimal tidak mampu memperbaiki profil tegangan akibat kontingensi, sehingga pada studi ini akan dilakukan optimasi penempatan dan penentuan kapasitas SVC menggunakan Voltage Performance Index dan Quantum Swarm Evolutionary Algorithm (QSEA).
\end{abstract}

Kata Kunci-Voltage Security, Voltage Performance Index,Static VAR Compensator, Quantum Swarm Evolutionary Algorithm.

\section{PENDAHULUAN}

$\mathrm{O}$ PERASI sistem tenaga listrik yang baik dan aman dapat diperoleh dengan memasang Flexible AC Transmission System (FACTS) device [1] FACTS devices berbasis pada kontrol solid-state sehingga memungkinkan untuk dikontrol pada kecepatan yang jauh lebih tinggi. Namun, alokasi dan sizing optimal dari FACTS devices sangat penting untuk mendapatkan hasil yang terbaik. Beberapa pendekatan dan penelitian telah dilakukan untuk mencari lokasi dan ukuran SVC yang paling optimal dengan beberapa tehnik yaitu Genetic Algorithm (GA), Simulated Annealing (SA), Artificial Immune System (AIS) dan Particle Swarm Optimization (PSO) [2][3]. Pada [4], penempatan optimal dari hanya 1 SVC untuk mengurangi rugi-rugi daya, deviasi tegangan, dan biaya instalasi telah ditemukan menggunakan GA. Pendekatan berbasis PSO juga telah diterapkan untuk mencari lokasi optimal dari SVC pada sistem IEEE 30 bus pada [5]. Penelitian ini akan menampilkan hasil penerapan Algoritma Quantum
Swarm Evolutionary (QSEA) untuk menentukan lokasi dan ukuran optimal dari SVC pada sistem transmisi $500 \mathrm{kV}$ Jamali tahun 2017 pada kondisi kontingensi terparah. Peringkat kontingensi untuk line outage ditentukan dengan menggunakan Voltage Performance Index (VPI).

\section{METODOLOGI}

\section{A. Metode Penelitian}

Pada pengerjaan Studi ini dilakukan beberapa tahapan mulai dari pengumpulan data, permodelan sistem hingga pembuatan program simulasi. Tahapan pengerjaan Studi ini dapat dilihat pada diagram alir berikut:
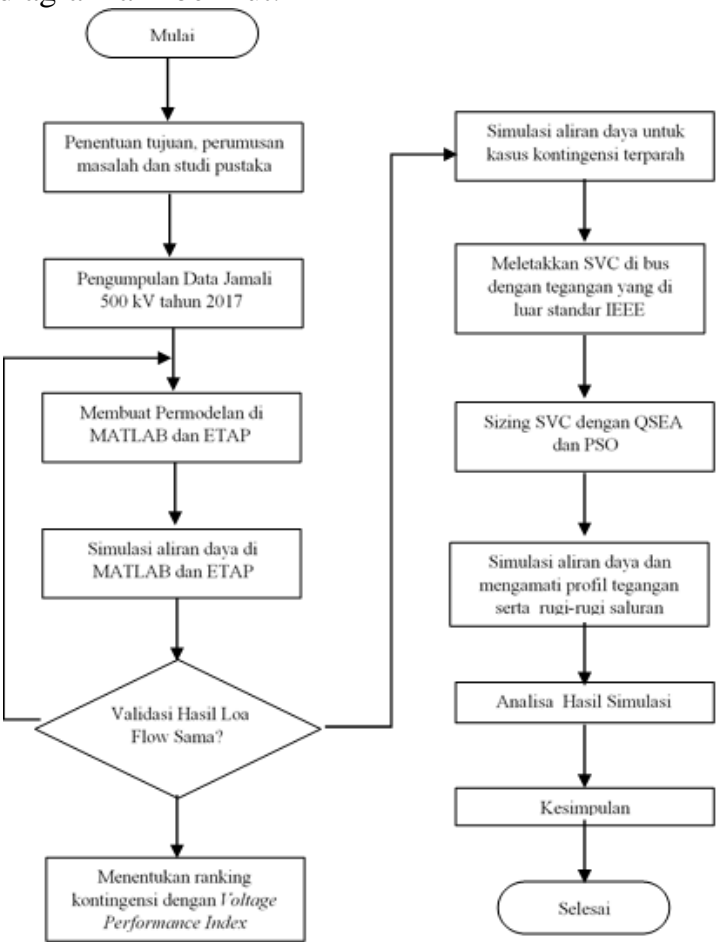

Gambar 1. Diagram Alir Studi

\section{B. Sistem Kelistrikan Jamali 2017}

Data sistem yang digunakan dalam Studi ini adalahdata sistem kelistrikan Jawa-Madura-Bali $500 \mathrm{kV}$ tahun 2017 yang yang diperoleh dari PT. PLN P2B (Pusat Pengatur Beban) Gandul, Depok, Jakarta per tanggal 24 Maret 2017. Data yang diperoleh berupa logsheet yang selanjutnya diolah sesuai dengan permodelan yang telah ditentukan. 
Sistem kelistrikan Jawa-Madura-Bali $500 \mathrm{kV}$ tahun 2017 terdiri dari 30 gardu induk. Sistem Jamali $500 \mathrm{kV}$ tahun 2017 terdiri dari 30 bus ( 1 buah slack bus, 9 PQ generator bus dan 20 load bus) dan 35 saluran transmisi. Sistem ini memiliki tegangan bus sebesar $500 \mathrm{kV}$ dan base daya 100 MVA. Single line diagram sistem kelistrikan Jamali $500 \mathrm{kV}$ tahun 2017 ditunjukkan oleh Gambar 2.

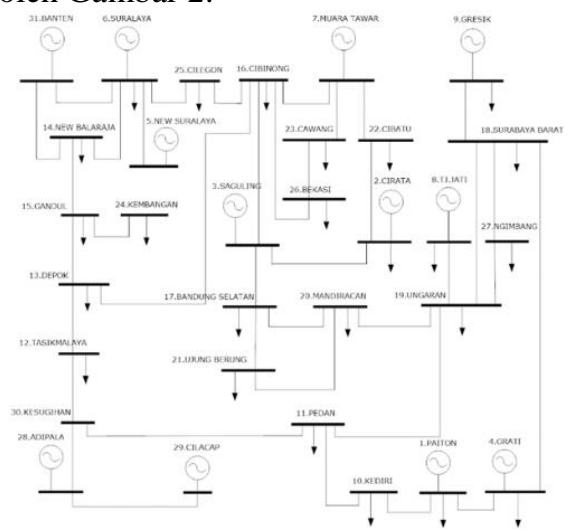

Gambar 2. Single Line Diagram Sistem Kelistrikan Jamali 500 kV Tahun 2017

\section{Voltage Performance Index}

Indeks kontingensi pada bus atau saluran merupakan variabel yang menunjukkan apakah operasi sistem pasca kontingensi aman atau tidak. Indeks kontinjensi digunakan untuk menentukan saluran transmisi yang menyebabkan kondisi kritis terhadap sistem saat dieliminasi. Beberapa metode dapat digunakan untuk menentukan indeks kontingensi, salah satunya seperti Voltage Performance Index (VPI) [6]. Dengan menggunakan indeks kontingensi, skenario terburuk line outage dapat diperoleh. Skenario ini memiliki efek paling kritis jika sistem dioperasikan terus menerus setelah kejadiannya [7]. Persamaan Voltage Performance Index dapat ditulis sebagai berikut:

$$
V P I=\sum_{i=1}^{N B}\left(\frac{\Delta\left|V_{i}\right|}{\Delta\left|V_{i}^{\text {max }}\right|}\right)^{2 m}
$$

Dimana:

$\Delta\left|V_{i}\right|=$ absolut selisih antara tegangan kontingensi dan tegangan base case

$\Delta\left|V_{i}^{\text {max }}\right|=$ Batas tegangan yang diizinkan selama kontingensi

\section{Static VAR Compensator (SVC)}

Static VAR Compensator adalah FACTS device yang dapat menyuplai static var yang dapat dikontrol. SVC terdiri dari kombinasi kapasitor, reaktor, dan thyristor sebagai pengendali. SVC dioperasikan berdasarkan nilai tegangan. Bila level tegangan rendah SVC akan menginjeksi daya reaktif ke sistem dan sebaliknya. Jumlah daya reaktif yang disuntikkan dikendalikan oleh sudut penyalaan thyristor [8].

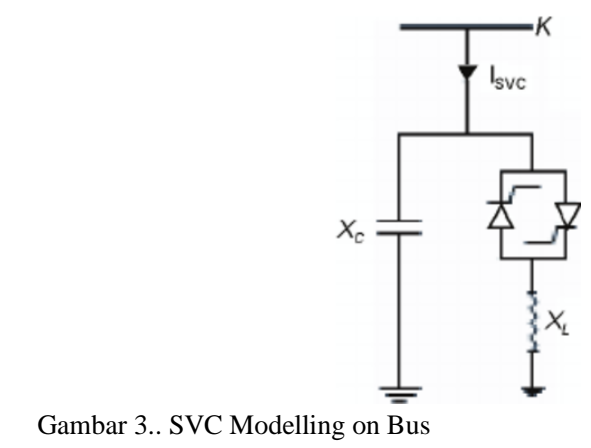

Persamaan induktor SVC berdasarkan sudut penyalaan thyristor:

$$
\begin{gathered}
B_{L(\alpha)}=-\frac{1}{\omega L}\left(1-\frac{2 \alpha}{\pi}-\frac{\sin (2 \alpha)}{\pi}\right. \\
B_{S V C}=B_{L(\alpha)}+B_{C}=\omega C
\end{gathered}
$$

Thyristor firing angle is ranged from 0 to 90 degree

\section{E. Quantum Evolutionary Swarm Optimization}

QEA diusulkan oleh Han [9] yang terinspirasi dari konsep komputasi kuantum. Pada QEA, satuan informasi terkecil disebut Q-bit, yang didefinisikan sebagai $\left[\begin{array}{l}\alpha \\ \beta\end{array}\right]$, dimana $\alpha$ dan $\beta$ adalah bilangan kompleks yang menspesifikasi amplitude probabilitas pada keadaan masing-masing. $|\alpha|^{2}+|\beta|^{2}=1$.

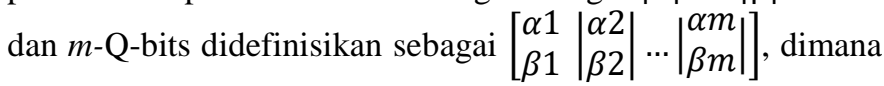
$|\alpha \mathrm{i}|^{2}+|\beta \mathrm{i}|^{2}=1(\mathrm{i}=1,2, \ldots, m)$ dan $\mathrm{m}$ adalah jumlah Q-bits [10].

Untuk mengadopsi PSO agar bisa memperbarui Q-bit secara otomatis maka kita perlu mendefinisikan quantum angle. Quantum angle didefinsikan sebagai sudut yang bisa berubahubah $\theta$ dan Q-bit sebagai [ $\theta]$.

Kemudian $[\theta]$ adalah ekuivalen terhadap Q-bit orisinal sebagai $\left[\begin{array}{l}\sin (\theta) \\ \cos (\theta)\end{array}\right]$. Memenuhi $|\sin (\theta)|^{2}+\mid \cos \left(\left.\theta\right|^{2}=1\right.$ secara langsung. Kemudian m-Qbits dapat digantikan dengan $\left[\theta_{\mathrm{i}}{ }^{\prime}\right]=$ $\left[\theta_{\mathrm{i}}+\zeta\left(\Delta \theta_{\mathrm{i}}\right)\right][10]$

Prosedur QSEA dapat disimpulkan sebagai berikut:

1. Menggunakan Quantum angle untuk membentuk Q-bit $\mathrm{Q}(\mathrm{t})=\left\{\mathrm{q}_{1}^{\mathrm{t}}, \mathrm{q}_{2}^{\mathrm{t}}, \ldots, \mathrm{q}_{\mathrm{n}}^{\mathrm{t}}\right\}, \mathrm{q}_{\mathrm{j}}^{\mathrm{t}}=\left[\theta_{\mathrm{j} 1}^{\mathrm{t} 1}\left|\theta_{\mathrm{j} 2}^{\mathrm{t}}\right| \ldots \mid \theta_{\mathrm{jm}}^{\mathrm{t}}\right]$.

2. Membuat setiap $\mathrm{x}_{\mathrm{ji}}^{\mathrm{t}}=0$ atau 1 dari $\mathrm{P}(\mathrm{t})$ dengan mengamati kondisi $\mathrm{Q}(\mathrm{t})$ melalui $\left|\cos \left(\theta_{i j}\right)\right|^{2}$ atau $\left|\sin \left(\theta_{i j}\right)\right|^{2}$ sebagai berikut:

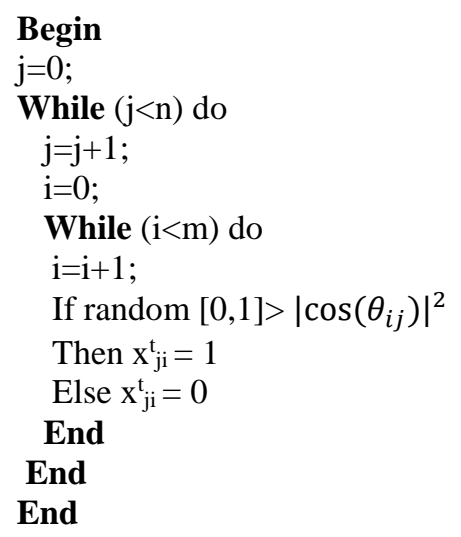


3. Modifikasi prosedur perbaruan untuk memperbarui $\mathrm{Q}(\mathrm{t})$ dengan rumus improved PSO menggantikan Qgate $\mathrm{U}(\mathrm{t})$ tradisional

$$
\begin{aligned}
& v_{j i}^{t+1}=\chi *\left(\omega * v_{j i}^{t}+C 1 * \text { rand } *\left(\theta_{j i}^{t}(\text { pbest })-\theta_{j i}^{t}\right)+C 2 *\right. \\
& \text { rand } \left.*\left(\theta_{j i}^{t}(\text { gbest })-\theta_{j i}^{t}\right)\right) \\
& \theta_{j i}^{t+1}=\theta_{j i}^{t}+v_{j i}^{t+1}
\end{aligned}
$$

Dimana $v_{j i}^{t}, \theta_{j i}^{t}, \theta_{j i}^{t}$ (pbest) dan $\theta_{j i}^{t}$ (gbest) adalah kecepatan, posisi sekarang, individual best dan global best dari Q-bit ke-i dan $\mathrm{m}$-Qbits ke-j, secara berturut-turut. Atur $\chi=0.99, \mathrm{~W}=$ $0.7928, \mathrm{C} 1=1.42, \mathrm{C} 2=1.57$, yang memenuhi kondisi konvergen partikel: $\mathrm{W}>(\mathrm{C} 1+\mathrm{C} 2) / 2-1$. Karena $\mathrm{C} 2>\mathrm{C} 1$, partikel akan lebih cepat konvergen menuju posisi optimal global dari kawanan dibandingkan posisi optimal lokal dari tiap partikel.[11]

Masalah yang ditunjukkan disini adalah untuk menentukan tempat dan ukuran SVC yang optimal untuk meminimalkan nilai indeks VPI dan biaya investasi SVC. VPI digunakan untuk menentukan rangking kontingensi. Dari sudut pandang pelanggaran batas tegangan bus, tingkat keparahan kontingensi dihitung menggunakan VPI [6]. Masalah penempatan SVC bisa dijelaskan oleh fungsi obyektif dan konstrain berikut:

\section{Voltage Performance Index (VPI)}

Dari sudut pandang pelanggaran batas tegangan bus, tingkat keparahan kontingensi dihitung menggunakan VPI [4]. VPI indeks harus memiliki nilai seminim mungkin untuk menjaga sistemtetap aman. Objektif pertama adalah untuk meminimalkan indeks VPI yang dihitung dengan persamaan (1) sehingga:

2. Biaya investasi SVC

$$
f_{1}=V P I
$$

Berdasarkan Database AG Siemens [9], fungsi objektif biaya investasi untuk SVC dalam satuan (US\$/kVar) adalah sebagai berikut:

Cost $=0.0003 S^{2}-0,3051 S+127,38$

Sehingga:

$$
f_{2}=\text { Cost }
$$

Untuk menyelesaikan permasalahan optimasi yang non linear maka dapat digunakan fungsi objektif dengan beberapa kriteria yaitu:

$$
F=\min \left[f_{1}+f_{2}\right]
$$

\section{HASIL DAN ANALISIS}

Voltage Performance Index digunakan untuk menentukan kontingensi paling parah di sistem $500 \mathrm{kV}$ Jawa Balisistem ini memiliki 1 SLACK bus, 9 bus PQ, 20 bus beban dan 36 jalur transmisi. Dari hasil perhitungan diperoleh line outage dari bus 1 ke bus 4 adalah kontingensi paling parah dengan nilai VPI sebesar 0,1738. Di bawah kontingensi ini, beberapa batas tegangan bus dilanggar dan mungkin berbahaya jika dioperasikan. Ditunjukkan oleh kenaikan nilai VPI. Kontingensi pada saluran 1 yang menghubungkan Bus 1 Pembangkit Paiton dengan Bus 4 Pembangkit Grati merupakan kontingensi terparah dengan nilai VPI sbesar 0,1737. Analisis aliran daya dilakukan pada kondisi inbi untuk mengamati nilai tegangan pada bus dan rugi-rugi daya pada saluran. Dari Gambar 3 dapat dilihat bahwa terdapat perubahan nilai tegangan pada bus setelah kontingensi. Penyimpangan tegangan yang cukup signifkan terjadi pada bus 10 dan 11 dengan nilai tegangan sebesar 0.848 dan 0.9032 p.u. Nilai tegangan pada kedua bus tersebut telah berada di bawah batas toleransi normal tegangan yaitu 0.95 p.u. Sedangkan bus lain masih berada pada batas normal.

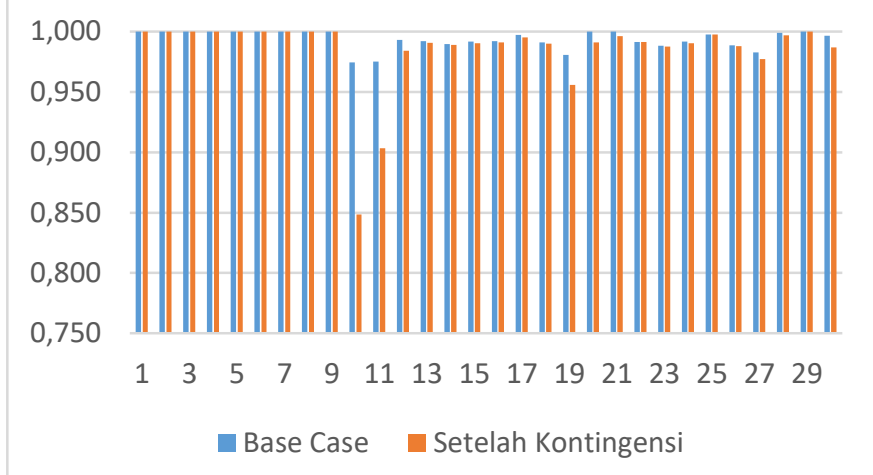

Gambar 4. Grafik Tegangan Bus sebelum dan setelah Kontingensi pada saluran 1

Oleh karena itu, pada sub bab ini dilakukan simulasi penempatan SVC pada bus yang memiliki profil tegangan buruk pada kasus kontingensi line outage pada saluran no 1 yang menghubungkan bus 1 dan 4 . Ukuran optimal SVC didapatkan dengan menggunakan metoda QSEA (Quantum Swarm Evolutionary Algorithm). Metode ini digunakan untuk mencari ukuran SVC pada bus 10 dan 11 secara simultan dengan batasan tegangan dan fungsi objektif VPI dan biaya instalasi SVC. Setelah didapatkan ukuran optimal SVC pada bus 10 dan 11 maka dilakukan analisis aliran daya kembali untuk melihat perubahan nilai profil tegangan dan rugi-rugi daya. Dari hasil QSEA didapatkan ukuran optimal SVC sebesar 695.213 MVAR dan pada bus 11 dengan ukuran sebesar 236.387 MVAR. Setelah SVC dipasang nilai VPI turun menjadi 0,000448 .

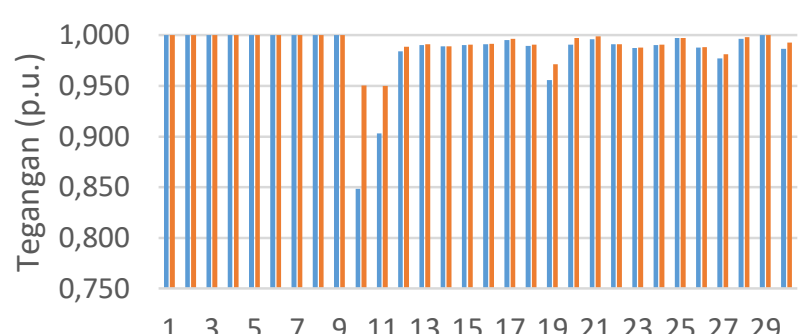

Bus

- Sebelum Pemasangan SVC $\quad$ Setelah Pemasangan SVC

Gambar 5. Grafik Tegangan Bus sebelum dan setelah pemasangan SVC dengan metode optimasi QSEA (Quantum Swarm Evolutionary Algorithm) Kontingensi pada Saluran 1.

Dari gambar 5 di atas dapat diamati bahwa nilai tegangan bus pada sistem meningkat. Tegangan pada bus 10 dan 11 yang semula berada di bawah standar tegangan sudah meningkat menjadi 0.951 dan 0.95 p.u. secara berturut-turut.

Dari hasil analisis aliran daya didapatkan bahwa pemasangan optimal SVC menggunakan metode QSEA dapat memperbaiki 
profil tegangan setelah terjadinya kontingensi dengan nilai VPI yang semula 0,1737 menjadi 0,000448 serta dapat menurunkan rugi-rugi daya aktif yang semula 347.517 MW menjadi 280.633 MW . Metode optimasi QSEA dapat menentukan nilai kapasitas optimal SVC untuk lebih dari 1 bus secara simultan dengan waktu untuk mencapai konvergensi yang relatif cepat. Grafik konvergensi optimasi ukuran SVC menggunakan metode QSEA dapat dilihat pada gambar berikut:

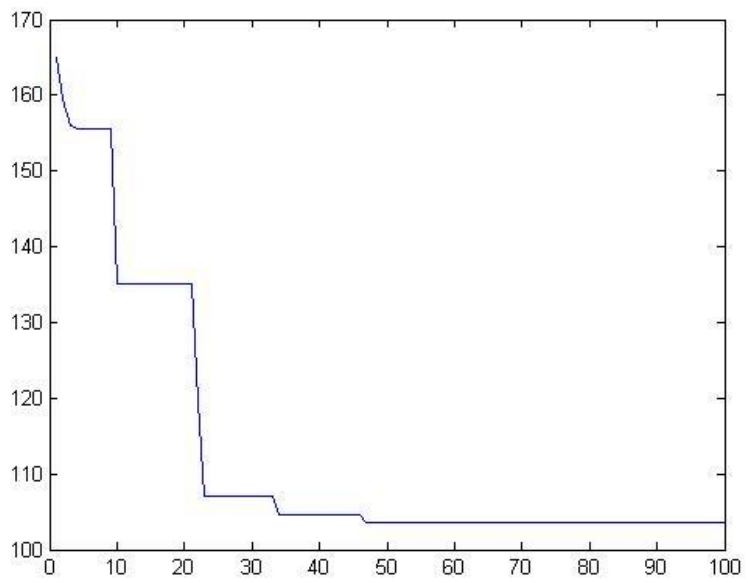

Gambar 6. Grafik konvergensi optimasi penempatan SVC menggunakan metode QSEA dengan Kontingensi pada Saluran 1.

\section{KESIMPULAN}

Dalam studi ini, Quantum Swarm Evolutionary Algotirhm telah berhasil diterapkan untuk mencari lokasi dan ukuran SVC yang optimal untuk meningkatkan keamanan tegangan pada sistem. Sehingga dapat disimpulkan bahwa penentuan lokasi dan ukuran yang optimal dari SVC dapat meningkatkan keamanan tegangan pada sistem.

\section{DAFTAR PUSTAKA}

P. S. Saravanan M., Slochanal S.M.R., Venkatesh P. and A. J, "Application of particle swarm optimization technique for optimal location of FACTS devices considering cost of installation and system loadability," Electr. PowerSystem Res., vol. 77, pp. 276-283, 2007.

[2] C. A. Minguez R., Milano F., Zarate-Minano R., "Optimal Network Placement of SVC Devices," IEEE Trans. Power Syst, vol. 22, no. 4, pp. 1851-1861, 2007.

[3] S. S. C. Singb 1G., Singh S. N., "A Approach for Optimal Placement of Static VA Compensators Based on Reactive Power Spot Price," IEEE Trans. Power Syst, vol. 22, no. 4, pp. 2021-2029, 2007.

[4] E. M. Pisica I., Bulac C., Toma L., "Optimal SVC Placement in Electric Power Systems Using a Genetic Algorithms Based Method," IEEE Bucharest Power Tech Conf., pp. 1-6, 2009.

[5] S. Sundareswaran K., Hariharan B., Parasseri F. P., Antony D.S. and B, "Optimal Placement of Static Var Compensators (SVC's) Using Particle Swarm Optimization," Int. Conf. Power, Control Embed. Syst. PCES), pp. 1-4, 2010.

[6] A. J. Wood, Power Generation, Operation, and Control. New Jersey: Wiley \& Sons, 2014.

[7] and G. A. L. Srivastava, S. Dixit, "Optimal location and size of TCSC for voltage stability enhancement using PSO-TVAC," in Power and Energy System Conference: Towards Sustainable Energym Bangalore, 2014, pp. 1-6.

[8] V. R. B. and D. C. D. A. Mishra, V. N. K. Gundavarapu, "Real power performance index and line stability index-based management of contingency using firefly algorithm," IET Gener., vol. 10, no. 10, pp. 2327-2335, 2016

[9] D. O. K.Habur, "Flexiable AC transmission system, for cost effective and Reliable Transmission of Electrical Energy," htp://www.siemenstd.com. [Online]. Available: htp://www.siemenstd.com.

[10] J. H. K. K.H. Han, "Quantum-inspired evolutionary algorithm for a class of combinatorial optimization," IEEE Trans. Evol. Comput, pp. 580-593, 2002.

[11] C.-G. Wang, Yan., Feng, Xiao-Yu., Huang, Yan-Xin., Pu, DongBing., Zhou, Wen-Gang., Liang, Yan-Chun., Zhou, "A novel quantum swarm evolutionary algorithm and its applications," Elsevier Neurocomputing, pp. 633-640, 2006. 